\title{
Allylation Reactions in Aqueous Media: Development, Applications and Future Works
}

\author{
Teck-Peng, Loh* and Guan-Leong Chua \\ Division of Chemistry and Biological Chemistry, School of Physical and Mathematical Sciences, \\ Nanyang Technological University,
}

Received July 27, 2005

\begin{abstract}
The use of allyltin, allylzinc and allylindium in the allylation of carbonyl compounds are facile methods for the syntheses of homoallylic alcohols. These water-stable complexes frequently allow for reaction conditions that are not only mild, but also permit the dispensing of organic solvents as reaction media. These synthesis methodologies are progressively being developed for stereoselective carbon-carbon bond formations for the purpose of assembling complex natural products.
\end{abstract}

\section{Introduction}

The traditional paradigm of carbon-carbon bond formation under harsh conditions with strict protocols is now being challenged through the discovery of alternative chemistries that offer synthetic chemists mild and process-tolerant procedures. In particular, allyltin, allylzinc and allylindium ${ }^{1}$ chemistries are poised to replace traditional Grignard procedures. ${ }^{2}$ The use of these peculiar organometallic compounds for the allylation of carbonyl compounds ${ }^{3,4}$ to form homoallylic alcohols are important reactions in the synthesis of biologically active molecules such as polyketides ${ }^{5}$, macrolides ${ }^{6}$, polyhydroxylated natural products ${ }^{7}$ and polyether antibiotics. ${ }^{8}$ In general, the allylmetal complex is formed in situ from the corresponding allylic halide and metal powder followed by the reaction with the carbonyl compounds, with or without the presence of acid catalysts (Figure 1). Varying proportions of water are tolerated, and frequently, even promoting the reaction. However, substrate sensitivity to water and other factors sometimes make aqueous-based reactions not fruitful or feasible, despite the inherent capabilities of such systems.

$$
\mathrm{X}=\mathrm{Br}, \mathrm{X} \mathrm{R}^{1}, \mathrm{R}^{2}=\text { alkyl, aryl }
$$

Figure 1. General procedure for the allylation of carbonyl compounds.

In this account of our group's research in this field, we would take the reader from the early developments to present chemistries, and our recent foray into enantioselective allylation reactions. We would also be discussing applications of these allylation reactions to the synthesis of natural products, with an overview of our strategies and a brief description of the problems we encountered and the interesting results obtained.

\section{Development of Methodologies}

Our early set of work focused on the stereoselective implementation of the allylation in aqueous media. A diastereoselective allylation of a chiral sugar derivative ${ }^{9}$ was first studied and $\mathrm{Yb}(\mathrm{OTf})_{3}{ }^{10}$ was found to effectively catalyse the allylation in $\mathrm{DMF} / \mathrm{H}_{2} \mathrm{O}$ mixture with excellent anti-diastereofacial selectivity and yield (Figure 2). Note that use of water alone can promote this reaction, albeit with lower diastereoselectivity. Interestingly, the isomer ratio was reversed with the use of allylsilane and $\mathrm{SnCl}_{4}$ in place of the allylbromide-In system. The stereochemical result of the aqueous system was explained through Felkin-Anh's ${ }^{11}$ or Cram's model ${ }^{12}$, whereas that for the allylsilane system was attributed to a chelation-controlled reaction trajectory ${ }^{13}$.

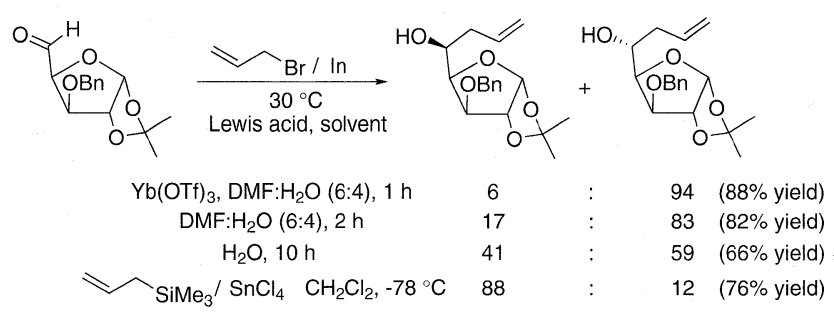

Figure 2. Indium-mediated allylation of a sugar derivative.

The above work was further extended to the allylation of $\alpha$-aminoaldehyde, foremost as a study on the effect of the nitrogen moiety on the diastereoselectivity. More importantly though, this could be a facile entry to enantiomerically pure $\beta$-amino alcohols that are present in many pharmacologically active compounds. Both indium- and zinc-mediated reactions were studied, with the results drawing a close parallel to the previously described glucose-derived aldehyde substrate (Figure 3). ${ }^{14}$ Note that zinc is unable to mediate the reaction in water alone, and this had prompted us to focus our attention on indium-mediated systems as part of our efforts to eliminate the use of organic solvents.

In our study on the stereochemistry of allylation for the purpose of natural product synthesis, we had found a stereoselective route to chiral tertiary alcohol through the allylation of a glucose-derived ketone (Figure 4). ${ }^{15}$ Excellent yields were obtained for this reaction and high diastereoselectivities were observed. Note that the use of $\mathrm{La}(\mathrm{OTf})_{3}$ or $\mathrm{Yb}(\mathrm{OTf})_{3}$ does not improve and even seems to reduce the diastereoselectivity in this reaction.

A chelation transition state was postulated to be responsible for the stereochemical outcome of the reaction (Figure 5). This is most likely the explanation for the reduced diastereoselectivities observed in the presence of an added Lewis acid. 


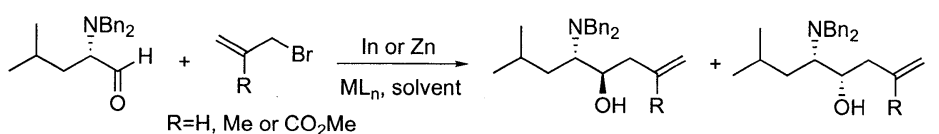

For $\mathrm{R}=\mathrm{H}\left\{\begin{array}{ccccc}\mathrm{In} / \mathrm{La}(\mathrm{OTf})_{3}, \mathrm{DMF}: \mathrm{H}_{2} \mathrm{O}(20: 1), 30 \mathrm{~min} & 92 & \vdots & 8 & (88 \% \text { yield }) \\ \operatorname{In}, \mathrm{DMF}: \mathrm{H}_{2} \mathrm{O}(20: 1), 5 \mathrm{~h} & 87 & \vdots & 13 & (82 \% \text { yield }) \\ \operatorname{In}, \mathrm{H}_{2} \mathrm{O}, 24 \mathrm{~h} & 73 & : & 27 & (82 \% \text { yield }) \\ \mathrm{Zn} / \mathrm{La}(\mathrm{OTf})_{3}, \mathrm{DMF}: \mathrm{H}_{2} \mathrm{O}(20: 1), 30 \mathrm{~min} & 91 & : & 9 & (94 \% \text { yield }) \\ \mathrm{Zn}, \mathrm{DMFF}: \mathrm{H}_{2} \mathrm{O}(20: 1), 5 \mathrm{~h} & 90 & \vdots & 10 & (88 \% \text { yield }) \\ \mathrm{Zn}, \mathrm{H}_{2} \mathrm{O}, 24 \mathrm{~h} & & \text { trace } & & \end{array}\right.$

Figure 3. In- or $\mathrm{Zn}$-mediated allylation of protected $\alpha$-aminoaldehyde.

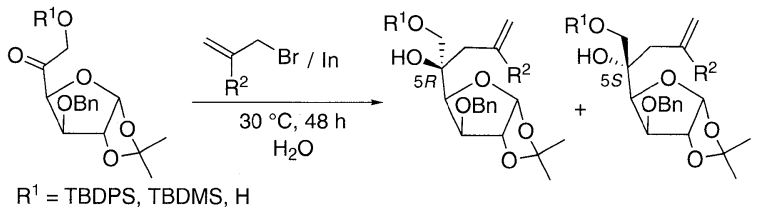

$\mathrm{R}^{2}=\mathrm{CO}_{2} \mathrm{Me}, \mathrm{H} \quad$ Yield $>97 \%, 5 R: 5 S>80: 20$

Figure 4. Indium-mediated allylation of sugar-derived ketone.

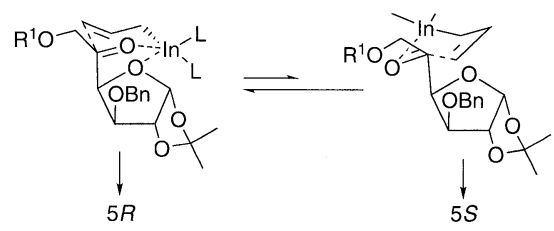

Figure 5. Proposed chelation transition state.

The competition of added Lewis acids for the chelation sites favoured by the indium center would have reduced the yield of the chelation product and instead, increased the proportion of the non-chelation product.

As part of our aim in developing reaction systems that function without any organic solvents, we developed a $\mathrm{Sn} / \mathrm{InCl}_{3}$ allylation system that demonstrated high diastereofacial selectivity in water (Figure 6). ${ }^{16}$ This $\mathrm{InCl}_{3}{ }^{17}$ catalysed reaction is proposed to occur through a transmetallation followed by a cyclic transition state to account for the strong anti preference of product formation. In the same paper, the allylation of various unprotected carbohydrates were also reported to have good to excellent yields with excellent diastereoselectivities.

As our laboratory is developing the chemistry of the $\mathrm{Sn} / \mathrm{InCl}_{3}$ system, we also had, at the same time, an interest in

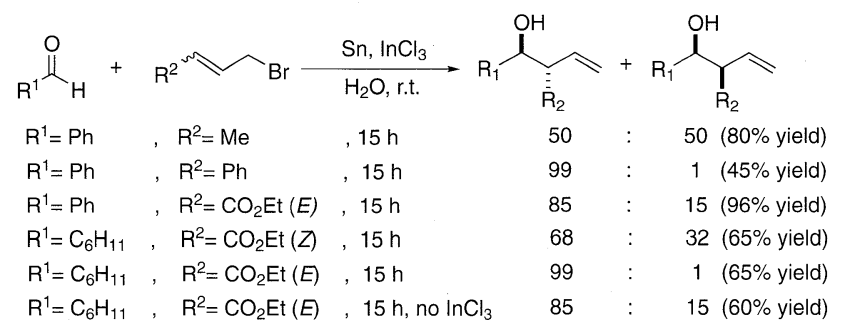

Figure 6. $\mathrm{InCl}_{3}$ promoted $\mathrm{Sn}$ mediated allylation of aldehydes in water.

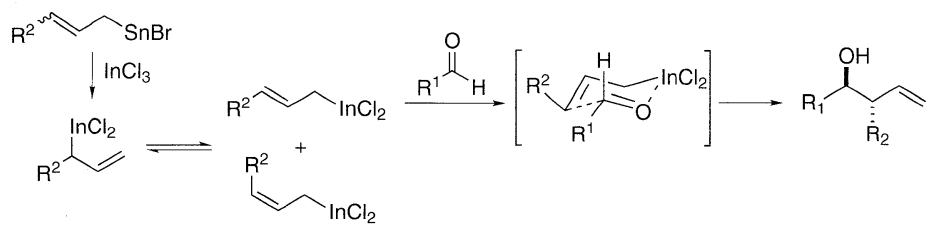

Figure 7. Proposed mechanism for the anti preference. the synthesis of fluorinated compounds. We first looked at methods to synthesize analogous compounds with trifluoromethyl group in place of methyl. The $\mathrm{CF}_{3}$ moiety, with its high $\mathrm{C}-\mathrm{F}$ strength, electron-withdrawing properties, both hydro- and lipo-phobicities, often impart unique properties to the equivalent hydrocarbon counterpart. ${ }^{18}$ This is especially so for pharmacologically active compounds. Thus, the $\mathrm{Sn} / \mathrm{InCl}_{3}$ allylation methodology was extended to the synthesis of $\beta$-trifluoromethylated homoallylic alcohols using a novel 1,1, 1-trifluoro-4-bromobut-2-ene as the allylic halide (Figure 8). ${ }^{19}$ Unlike previous observations, the reaction does not proceed without the catalysis of $\mathrm{InCl}_{3}$. Another result of note is the strong anti or syn preference that is substrate-dependent.

$$
\begin{array}{lll}
8 \text { (95\% yield }) \\
\text { (I) }
\end{array}
$$

Figure 8. Synthesis of $\beta$-trifluoromethylated homoallylic alcohols.

The above reaction is proposed to proceed via the same six-membered transition state as depicted in Figure 7 to result in the anti preference. However, the intense syn selectivity observed for 2-pyridinecarboxaldehyde and glyoxylic acid is explained through the bulky group of the aldehyde adopting the axial instead of the equatorial position as a result of a stabilizing five-membered ring chelation with the indium center (Figure 9).

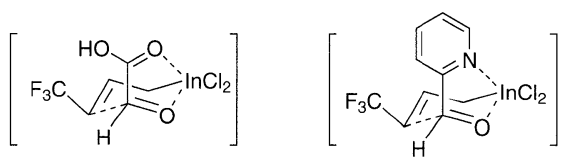

Figure 9. Proposed transition states to account for the preferential formation of syn products.

A purely indium-mediated counterpart to the above reaction was also studied and the results were excellent in terms of yields and diastereoselectivities. ${ }^{20}$ In addition, the anti and syn selectivities closely paralleled that of the $\mathrm{Sn} / \mathrm{InCl}_{3}$ system, and a similar transition state to account for the product stereochemistry is still pertinent. This simpler In-mediated allylation methodology was then adopted in preference over $\mathrm{Sn} / \mathrm{InCl}_{3}$ in our future work.

The study on the synthesis of organofluorine compounds continued with the synthesis of $\alpha$-trifluoromethylated alcohols through allylation of the corresponding fluorinated aldehyde. This seemingly straightforward reaction is hampered by the difficulty of handling trifluoroacelaldehyde, which is a volatile compound with a strong tendency to exist as its hydrated form. Hence, traditional organometallic addition to this aldehyde would be difficult, and a water-tolereant methodology would be highly sought after. The most convenient starting material is the commercially available trifluoroacetaldehyde ethyl hemiacetal. This, surprisingly, lends 
itself directly to our indium-mediated allylation without further treatment (Figure 10). ${ }^{21}$ Interestingly, in contrast to our past results, the product yield was attenuated by the addition of lanthanide triflates. In the same paper, the attempted use of a chiral auxiliary was unsuccessful. The use of the $\mathrm{Sn} / \mathrm{InCl}_{3}$ system was also studied and the results matches those of the In-mediated procedure as previously observed.

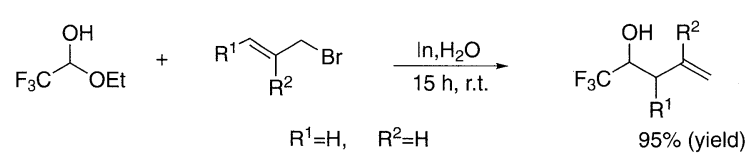

$$
\begin{aligned}
& \begin{array}{lll}
\mathrm{R}^{1}=\mathrm{H}, & \mathrm{R}^{2}=\mathrm{H} & 95 \%(\mathrm{y} \\
\mathrm{R}^{1}=\mathrm{H}, & \mathrm{R}^{2}=\mathrm{H} \text {, with 1 eq. La(OTf) } & 54 \%
\end{array} \\
& \mathrm{R}^{1}=\mathrm{H}, \quad \mathrm{R}^{2}=\mathrm{CO}_{2} \mathrm{CH}_{3} \quad 87 \% \\
& \mathrm{R}^{1}=\mathrm{CH}_{3}, \mathrm{R}^{2}=\mathrm{H} \quad 80 \% \\
& \mathrm{R}^{1}=\mathrm{H}, \quad \mathrm{R}^{2}=\mathrm{CO}_{2} \mathrm{H} \quad 65 \%
\end{aligned}
$$

Figure 10. Indium-mediated allylation of trifluoroacetaldehyde ethyl hemiacetal.

The unusual absence of the ethoxy product was explained through a cyclic transition state with the favored coordination of the "hard" hydroxyl group with the "hard" indium centre instead of the relatively "soft" ethoxy group (Figure 11).

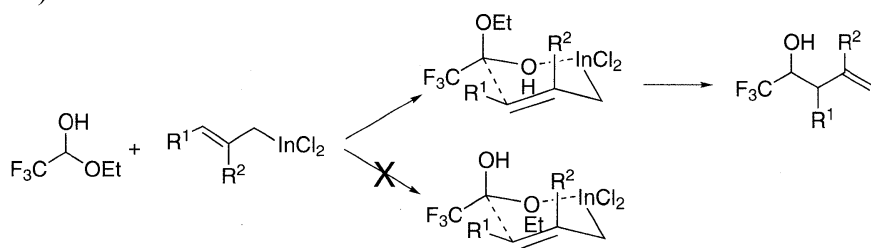

Figure 11. Mechanism proposed for the absence of ethoxy product.

Our continual search for alternative reaction systems that function well in water led us to the use of $\mathrm{CF}_{3} \mathrm{SO}_{3} \mathrm{H}$ as a Brønsted acid in the addition of allyltributylstannanes to aldehydes (Figure 12). ${ }^{22}$ Yields were good to excellent. Note that other mineral acids studied were not able to catalyse this reaction.

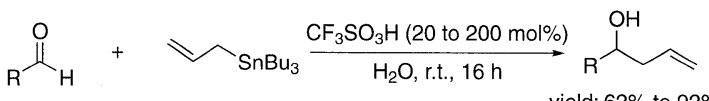

$$
\begin{aligned}
& \text { yield: } 62 \% \text { to } 92 \%
\end{aligned}
$$

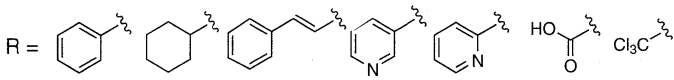

Figure 12. Addition of allyltributylstannanes to aldehydes in water catalysed by $\mathrm{CF}_{3} \mathrm{SO}_{3} \mathrm{H}$.

The preceding work was applied to the diastereoselective synthesis of oxysterols in a water/ethanol solvent system. High yields and diastereoselectivities were obtained (Figure 13). ${ }^{23}$

In the course of our study to find the optimum reaction media in indium-mediated allylations, we observed at the same time that the reaction media had a strong influence on
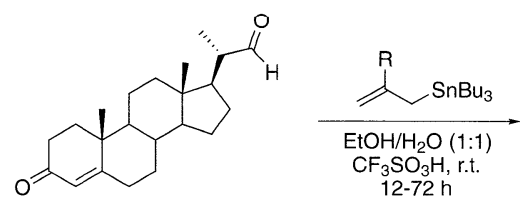

$\mathrm{R}=\mathrm{H}, \mathrm{CH}_{3}, \mathrm{CH}_{2} \mathrm{OH}, \mathrm{CH}_{2} \mathrm{OBz}$ or $\mathrm{CH}\left(\mathrm{CH}_{3}\right) \mathrm{OH}$

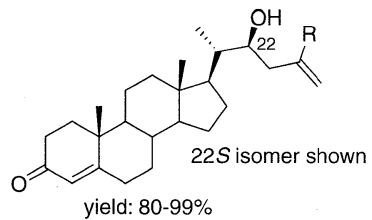

$22 S: 22 R>74: 26$

Figure 13. Diastereoselective synthesis of oxysterols. regioselectivities (Figure 14). ${ }^{24}$ Apparently, the $\gamma$-adduct is predominantly formed in organic and aqueous media, whereas the $\alpha$-adduct is preferentially formed in water. Water must also be present in a substantial amount at $10 \mathrm{M}$, with the. result from a $0.5 \mathrm{M}$ experiment giving us mainly $\gamma$ isomers. However, most importantly, this straightforward methodology allows for the formation of $\alpha$-adducts in In-mediated systems, in which such regiochemistry can only be coaxed through steric interactions ${ }^{25}$, di-indium complexes ${ }^{26}$ or rearrangements ${ }^{27}$.
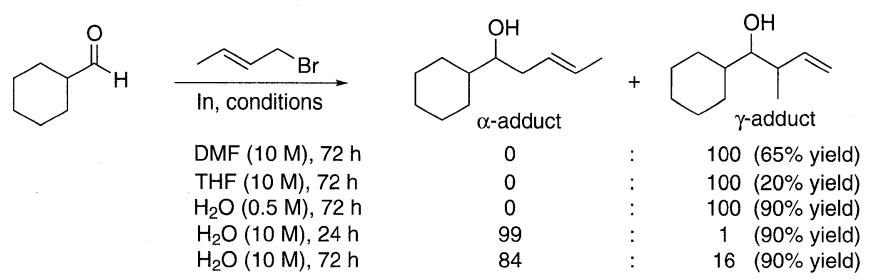

Figure 14. Highly regioselective indium mediated allylation through media selection.

The results suggest the possibility of an interesting mechanistic origin and this enticed our further investigation. ${ }^{28} \mathrm{We}$ started with following the course of the reaction between cyclohexane carboxaldehyde with crotyl bromide mediated by indium in $10 \mathrm{M}$ water (Figure 14). The reaction was complete with almost entirely the kinetically formed $\gamma$-adduct after $2 \mathrm{~h}$. After $4 \mathrm{~h}$, the $\alpha$-adduct appeared and all $\gamma$-adduct was converted to the thermodynamically formed $\alpha$-adduct after $24 \mathrm{~h}$. The reaction pathway of the thermodynamically controlled process was ascertained through a "cross-over experiment" (Figure 15). Results suggest the transient formation of the aldehyde and an allyl fragment.
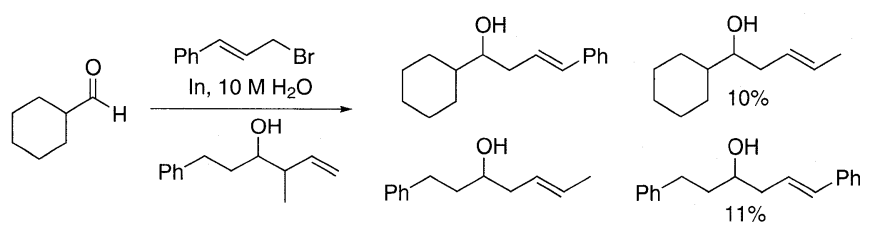

Figure 15. Cross-over experiment.

Another set of data that assisted us in determining the mechanism is the allylation of a steroidal aldehyde (Figure 16). The conclusive stereochemistry from the X-ray diffraction analysis of the products points to an inversion of the chiral centre at $\mathrm{C} 22$ following the proposed reattachment of the allyl fragment to form the $\alpha$-adduct. This anti-Cram product excluded the possibility of a "free" allyl fragment involved in the re-addition to the aldehyde.

The collated data converged to suggest a new mechanism for this indium-mediated allylation in water. This new proposed mechanism is not in line with the allyl anion transfer mechanism $^{29}$ or the mechanism arising from steric effects ${ }^{30}$. A bond cleavage generating the parent aldehyde followed by a concerted rearrangement, perhaps by a retro-ene ${ }^{31}$, with subsequent 2 -oxonia [3,3]-sigmatropic rearrangement ${ }^{32}$ is the most probable mechanism that fits all data (Figure 17). The entire investigation was completed with the study of the allylation using $\mathrm{Sn}$ and $\mathrm{Zn},{ }^{33}$ with the results being similar to that of the In-mediated reaction.

With the mechanism elucidated, our group pro- 


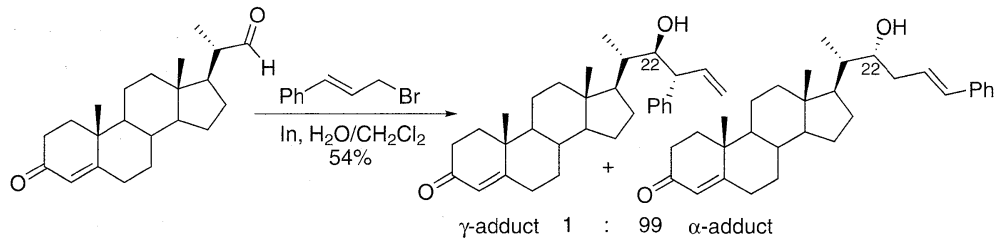

Figure 16. Stereochemical inversion at $\mathrm{C} 22$.

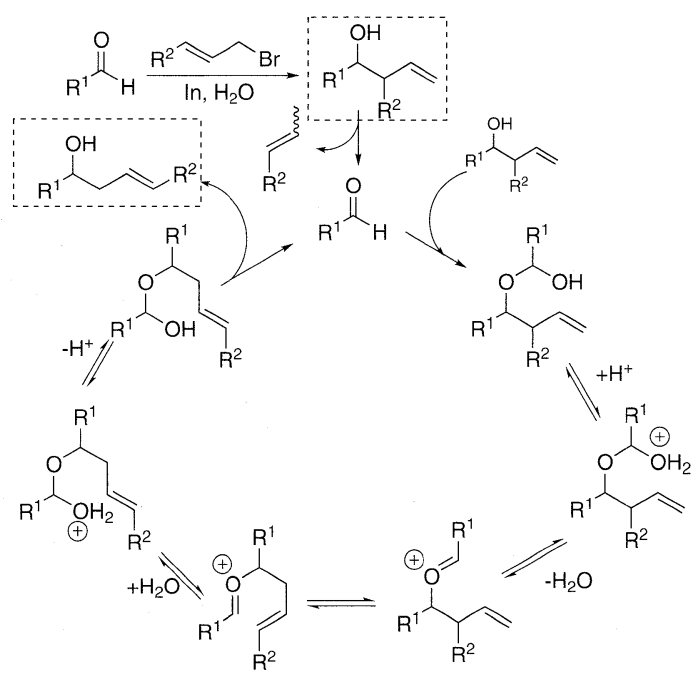

Figure 17. Proposed mechanism for rearrangement.

ceeded to exploit the applications of this novel reaction pathway in synthesis. Recent work had shown that the use of In $(\mathrm{OTf})_{3}$ as a catalyst with $\mathrm{CH}_{2} \mathrm{Cl}_{2}$ as solvent is a highly versatile implement for the further manipulation of homoallylic alcohols. Our group had reported the formation of tetrahydrofuran moieties through further oxyindiation reaction ${ }^{34}$, the synthesis of $22 \alpha-$ sterols $^{35}$ and an enantioselective allyl transfer reaction ${ }^{36}$. In some cases, yields and stereoselectivities were enhanced through the use of Brønsted acids ${ }^{37}$. However, the discussions of such chemistries are beyond the scope of this account. Efforts are being directed to adopt these procedures in aqueous systems, in line with our laboratory's direction in developing "green" chemical processes.

\section{Development of Enantioselective Allylation}

Our group's initial investigations into the enantioselective allylation through the use of chiral promoters made use of the In/organic solvent system, with (-)-cinchonidine or $(+)$-cinchonidine as chiral promoters (Figure 18). ${ }^{38}$ However, the enantiomeric excess was mostly moderate to good and achievable only through the use of excess chiral promoter $(2$ eq.). Most importantly, the protocol requires the use of dry organic solvents.

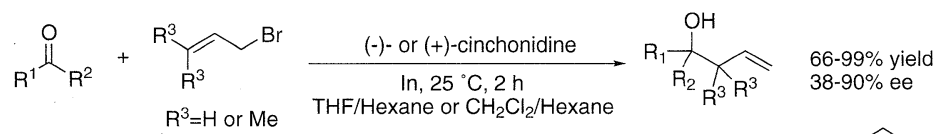
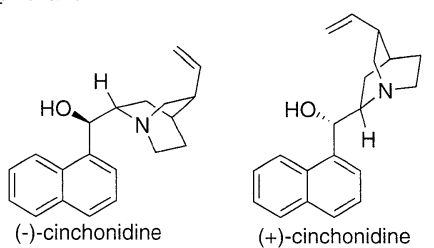

Figure 18. Enantioselective allylation using cinchonidine.
Following an earlier work by Nishiyama et $a l .{ }^{39}$, we proceeded to screen a series of potential $C_{2}$-symmetric chiral bis(oxazoline) ligands ${ }^{40}$ that might function well in aqueous systems. Initial results in $\mathrm{EtOH} / \mathrm{H}_{2} \mathrm{O}$ pointed to the superiority of the iPrPYBOX ligand, and further work with screening of Lewis acids resulted in an excellent yield of $90 \%$ and an enantiomeric excess of $92 \%$ with $\mathrm{Ce}(\mathrm{OTf})_{4}$ hydrate as Lewis acid (Figure 19). ${ }^{41}$ However, this procedure required the use of excess ligand and catalyst, and alternative systems that are more economical were sought.

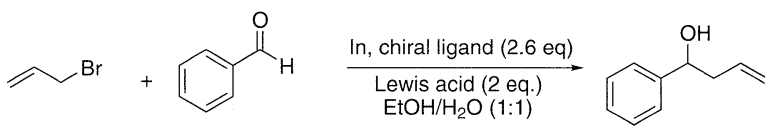

$90 \%$ yield, $92 \%$ ee $(R)$ with $\mathrm{Ce}(\mathrm{OTf})_{4}$ as Lewis acid

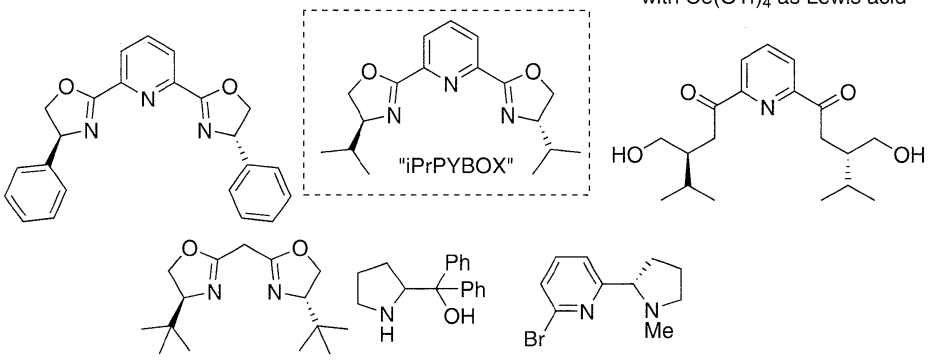

Figure 19. Enantioselective allylation reaction in aqueous medium.

Based on the work by Yamamoto and Yanagisawa et $a l .{ }^{42}$, we explored the use of a $(S)$-BINAP·AgOTf complex to develop a catalytic system for enantioselective allylation. Following the reported procedure, but using a $\mathrm{H}_{2} \mathrm{O} / \mathrm{EtOH}$ mixture instead of dry THF, we generated the complex by stirring $(S)$-BINAP and AgOTf at $25{ }^{\circ} \mathrm{C}$ for $30 \mathrm{~min}$ in the dark. Use of $5 \mathrm{~mol} \%$ of this catalyst for the reaction between benzaldehyde and allyltributyltin afforded the $(S)$-enriched product in $61 \%$ yield and $54 \%$ ee after $14 \mathrm{~h}$ of stirring in the absence of light. This encouraging result prompted us to screen a series of other chiral diphosphines and reaction conditions (Figure 20) and 66\% ee was achieved with $(S)$-TolBINAP at a temperature of $-40{ }^{\circ} \mathrm{C}$.

To further improve the above results, we surveyed the use of other transition metal complexing agents in place of AgOTf. Apparently, from the metals screened, only $\mathrm{Ag}(\mathrm{I})$ salts are active, and little effect was observed from the counterion. With the final choice of $\mathrm{Ag}\left(\mathrm{NO}_{3}\right)$, we studied the reaction with different aldehydes (Figure 21). Yields were good to excellent, with good ee were observed for aromatic aldehydes. However, the results for aliphatic, olefinic and acetylenic aldehydes were only low to moderate.

Although the use of the above BINAP system had produced some positive results, it was an unsatisfactory system. The use of $\operatorname{Ag}(\mathrm{I})$ salts had made mandatory the conduct of the entire reaction process in the dark. In addition, although good ee was obtained for aromatic aldehydes, other aldehydes gave poor results. This precluded the universal application of this catalyst as part of our synthetic tool. Our laboratory thus continued to search for new chiral complexes to address these shortfalls.

Most recently, our laboratory had found a con- 


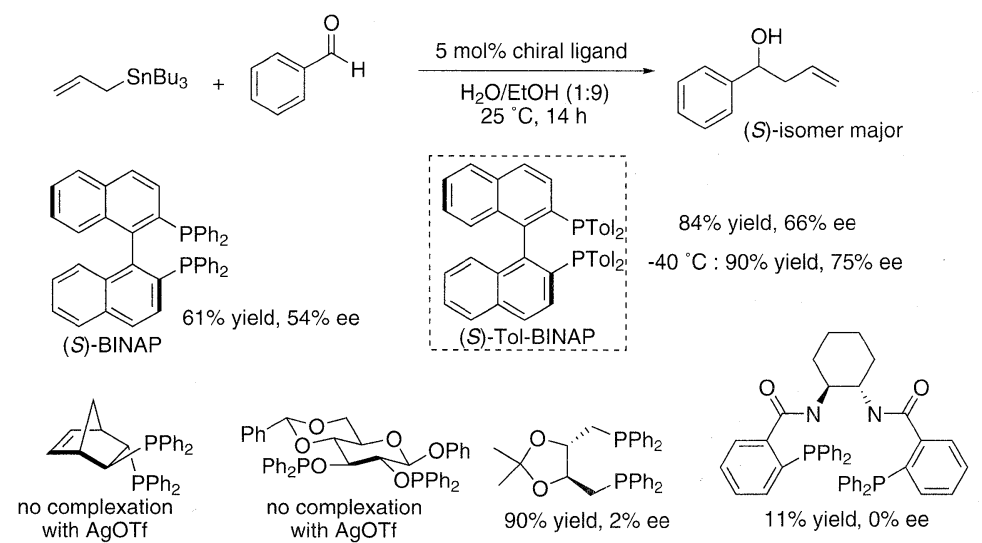

Figure 20. Catalytic enantioselective allylation.

molecule with carbon-carbon bond formations in aqueous medium. We envisioned that the assembly of the antillatoxin molecule could occur from two major fragments, 1 and 2 (Figure 23). The stereochemistry and structure of fragment 2 suggest that the $\mathrm{C} 4-\mathrm{C} 5$ bond may be formed from allylation of the conjugated aldehyde with an allylic bromide that possesses functional groups that could further be transformed to form the desired fragment.

The first work we embarked on was to carry out the allylation on the model aldehyde, cinnamaldehyde, using 2-bromocrotylbromide $(\mathrm{R} "=$ $\mathrm{Br}$ in Figure 23). ${ }^{47}$ Contrary to our established protocols, no reaction occurred through the use of the basic $\mathrm{In} / \mathrm{H}_{2} \mathrm{O}$ system. Addition of lanthanide

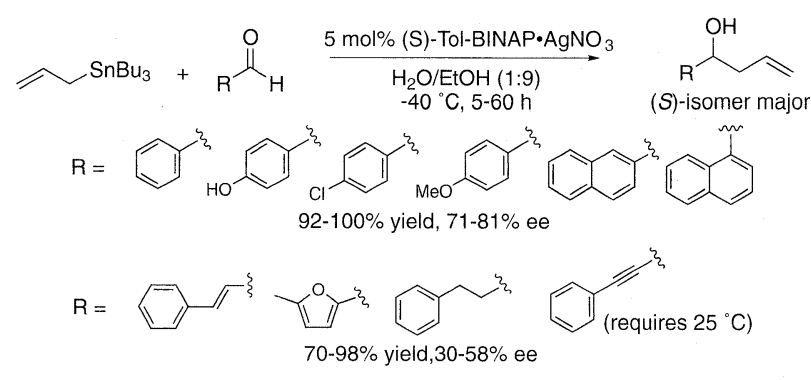

Figure 21. Catalytic enantioselective allylation using $(S)$-TolBINAP $\cdot \mathrm{AgNO}_{3}$.

venient method to form chiral indium complexes from In(III), the first reported case of such catalysts. Our first successful attempt was through the use of $(S)$-BINOL. The chiral complex was prepared simply by stirring $(S)$-BINOL with $\mathrm{InCl}_{3}$ in the presence of molecular sieves and $\mathrm{CH}_{2} \mathrm{Cl}_{2}$ as solvent. The formed $(S)$-BINOL-In(III) complex was used catalytically for the enantionselective allylation of aldehydes by allyltributyltin in dichloromethane (Figure 22). ${ }^{43}$ Moderate to good yields with consistently high enantioselectivities were obtained. Similar protocol and results were obtained with a chiral bis(oxazoline) ligand ("PYBOX"). ${ }^{44}$ Further investigations reveal the importance of the organotin reagent for the formation of the chiral indium complex. Our laboratory is currently focusing on adapting this system to the allylation in aqueous media.

\section{Applications of Allylation in Synthesis}

\subsection{Antillatoxin}

In order for methodologies to mature into useful routine synthetic tools, it is necessary to apply the developed concepts and procedures to the synthesis of complex molecules, in particular, the synthesis of natural products.

Antillatoxin, an ichthyotoxin isolated from a marine cyanobacterium (Lyngbya majuscula), was reported in 1995 by Orjala et al..$^{45}$ Its intriguing chemical structure and potent biological activity prompted several groups ${ }^{46}$, including us, to embark on its total synthesis. Our focus, however, was to assemble the

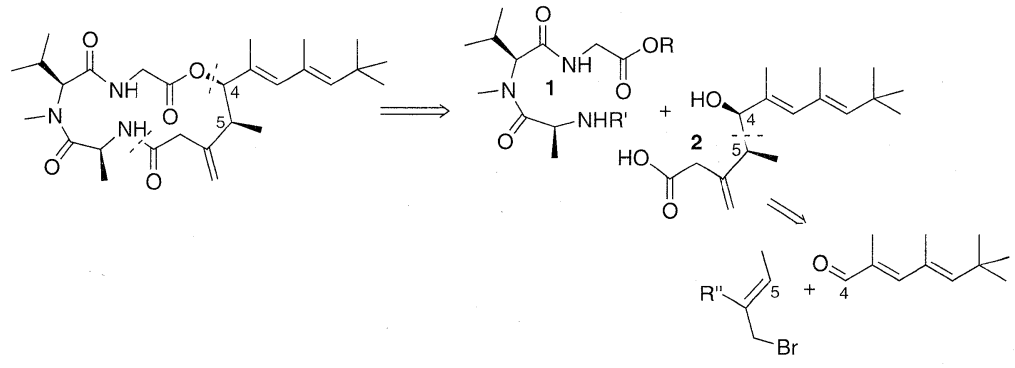

Figure 23. Retrosynthetic analysis of antillatoxin.

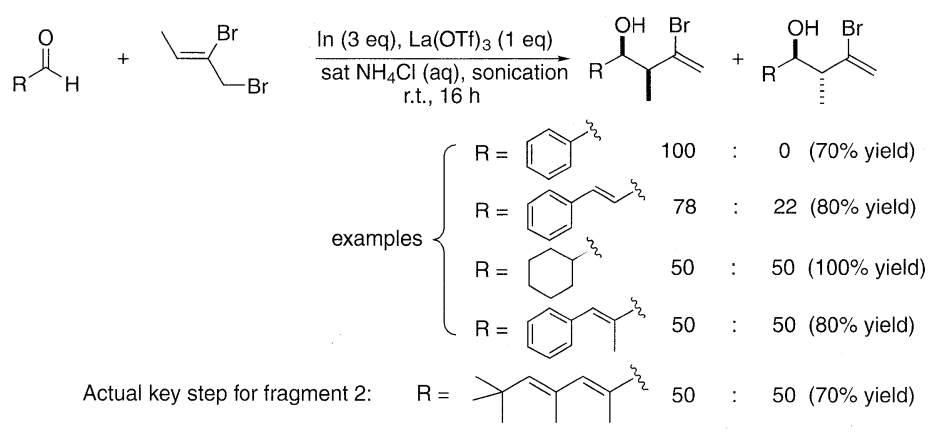

Figure 24. Modified optimum condition for allylation. 


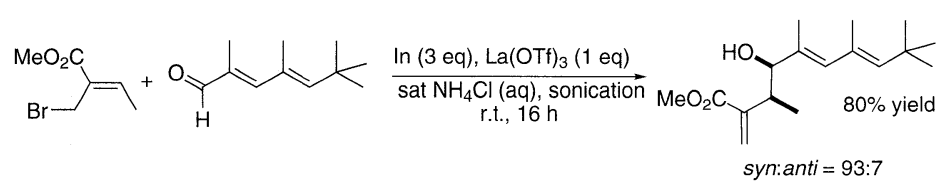

Figure 25. Diastereoselctive allylation to obtain target product.

(Z)-2-(bromomethyl)-2-butenoate and excellent syn preference was obtained, resulting in our desired target molecule in good yield (Figure 25). ${ }^{48}$

We were interested at that time in generating fragment 2 with the anti configuration, in addition to the correct syn configuration, at $\mathrm{C} 4-\mathrm{C} 5$ for the purpose of structure-activity studies. Our proposed transition state for the predominance of syn products could be explained by our previously reported cyclic transition state (Zimmerman-Traxler49). Hence, $E$-isomers are expected to give the anti product, whereas the $Z$-isomer is expected to give the syn product. Both $E-$ and $Z$ - isomers of 2-(bromomethyl)but-2-enyloxy(tert-butyl) diphenylsilane were then synthesized from methyl (Z)-2-(bromomethyl)-2-butenate. Study of the stereochemical outcome of the reaction was conducted using the above $\mathrm{In} / \mathrm{La}(\mathrm{OTf})_{3}$ system in $\mathrm{THF} / \mathrm{H}_{2} \mathrm{O}$. Yields and diastereoselectivities were consistently high, and contrary to our expectation, strong syn preferences for both geometric isomers were observed. From the fact that the reaction does not occur in the absence of $\mathrm{La}(\mathrm{OTf})_{3}$, and that the allylic bromide recovered after the reaction still retained the same configuration, an open-chain anti-periplanar transition state was proposed (Figure 26). ${ }^{50}$ Application of the procedure to the synthesis of fragment 2 resulted in good yields and diastereoselectivities. Note that a variation of this procedure was also reported by us in which $\alpha$-regioselectivity was obtained from a secondary allylic bromide, most likely through 1,3-allylic shift of the indium species which proceeded to react similarly to the preceding reaction. ${ }^{31}$

In the same paper, our group had also reported the use of (-)-cinchonidine (see Figure 18) in our attempts to realize the correct enantiomer at the same time. However, under the reaction conditions for the use of cinchonidine as a chiral promoter, no reaction occurred for the silyl protected allyl bromide. However, the reaction proceeded upon removal of the protecting group and facilitated the reaction to achieve good ee and excellent syn:anti ratio (Figure 27).

\section{2 (士)-Methylenolactocin and (士)-Phaseolinic Acid}

Methylenolactocin possesses interesting anti-tumor activity ${ }^{52}$. The high functionality and stereochemistry have made its synthesis a challenge for many research groups. ${ }^{53}$ Phaseolinic acid is a metabolite isolated from the fungus $M$. phaseolina $^{54}$, and is also a subject for synthetic studies ${ }^{55}$. Both natural products contain the $\alpha$-methylene- $\beta$-butyrolactone building block, which could be derived from an allylation reaction (Figure 28).
The allylic bromide was obtained in the $Z$ configuration from two steps starting with methyl acrylate. This was used in the In-mediated allylation of hexanal (Figure 29). With water alone, no products were obtained due to rapid formation of the undesired diester. Reducing the proportion of water with a $\mathrm{THF} / \mathrm{H}_{2} \mathrm{O}$ medium reduces diester formation and results in an equal proportion of anti and syn products. Interestingly, the anti product cyclizes to form the esterified target, the methylated form of $( \pm)$-methylenolactocin. The syn product could easily be cyclized and transformed to $( \pm)$-phaseolinic acid according to reported procedure. ${ }^{55}$ Hence, both products are useful in this synthesis. The yield of the desired product pair was good when the reaction was conducted in the absence of solvents. This procedure thus generates two highly advanced intermediate that could be transformed in a short and efficient manner to the two interesting natural products.

\subsection{Apoptolidin and FD-891}

Apoptolidin is a potent apoptosis-inducing agent isolated from Nocardiopsis sp. ${ }^{56}$, with the first total synthesis of this structurally intriguing and challenging compound reported recently by Nicolaou et. al. ${ }^{57}$ FD891 was isolated from the fermentation broth of Streptomyces graminofaciens A- $8890^{58}$

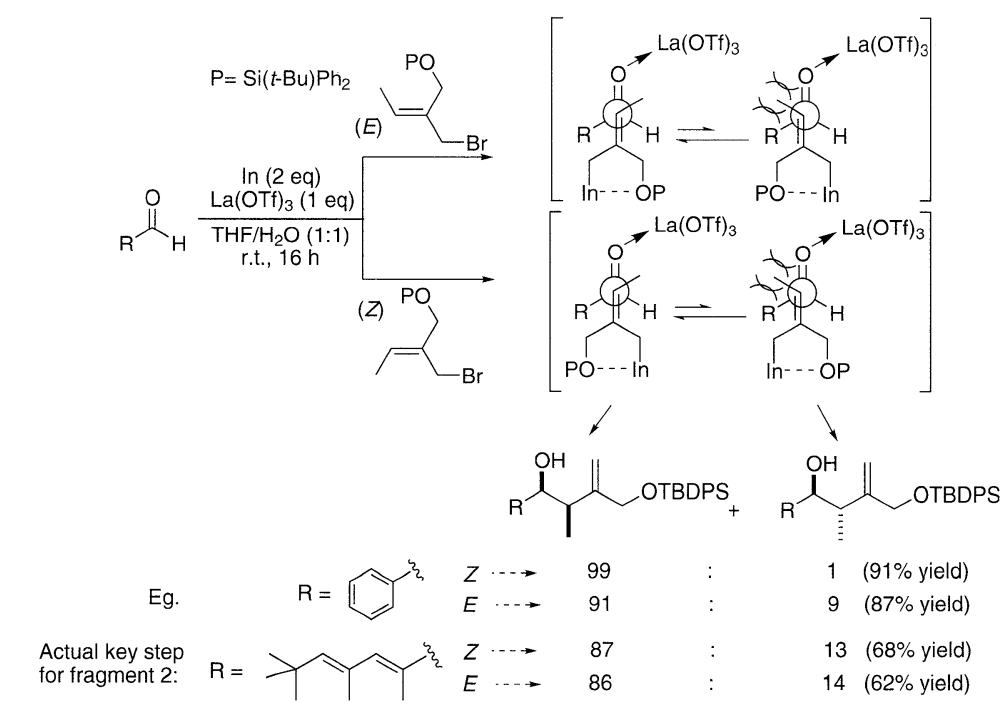

Figure 26. Proposed mechanism for observed diastereoselectivities.

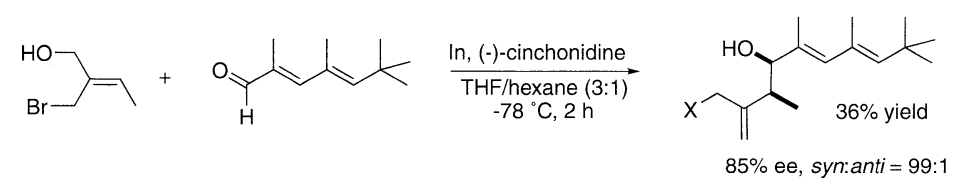

Figure 27. Enantioselective synthesis of fragment 2.

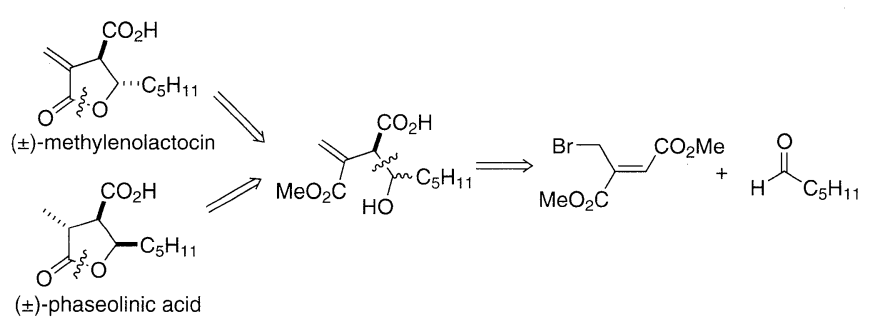

Figure 28. Retrosynthetic analysis of ( \pm )-methylenolactocin and $( \pm)$-phaseolinic acid. 


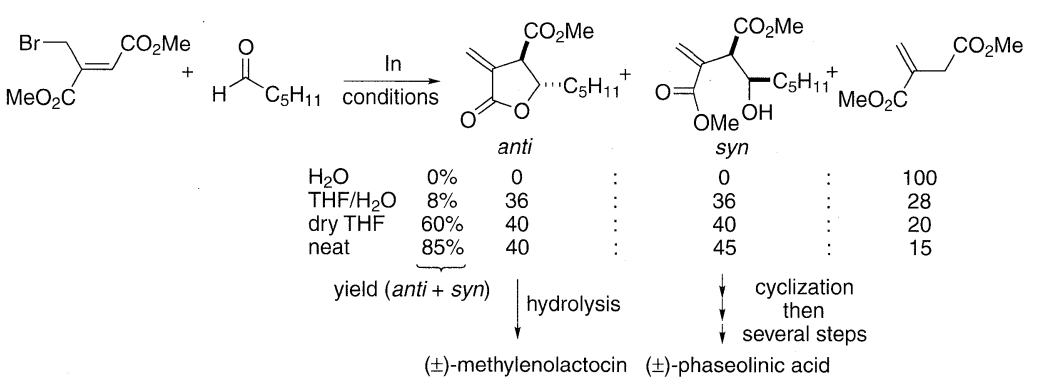

Figure 29. Optimizing the allylation of keto-ester.

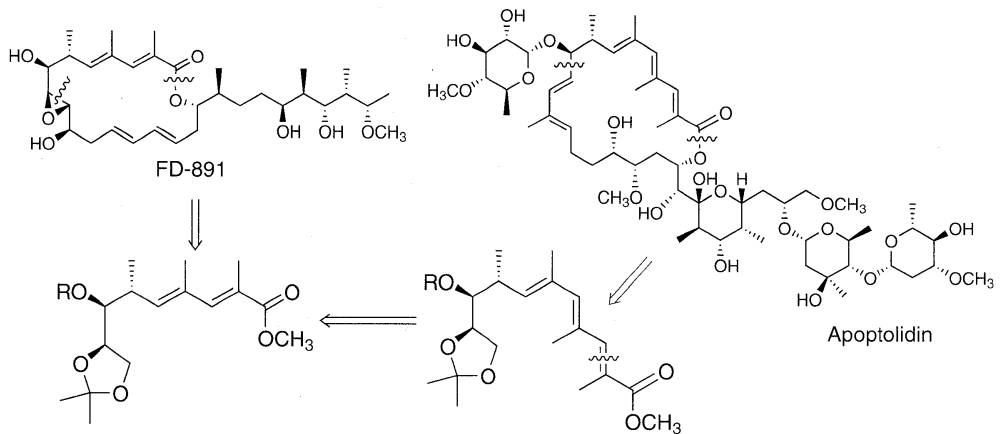

Figure 30. Retrosynthetic analysis of apoptolidin and FD-891 showing a common intermediate.

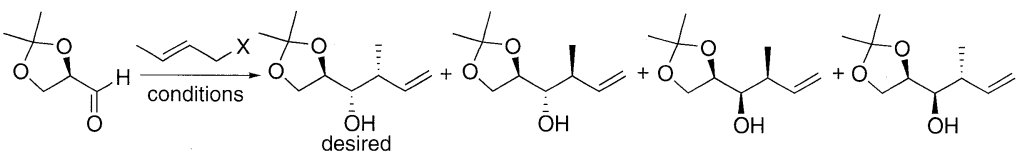

Best condition:

$\mathrm{X}=\mathrm{Br}, \mathrm{Sn}, \mathrm{Nal}$, TBAI, DMI- $\mathrm{H}_{2} \mathrm{O}$, r.t. $75 \quad$ :

Other examples:

$X=\mathrm{Br}, \mathrm{In}, \mathrm{H}_{2} \mathrm{O}$ r.t.

$\mathrm{X}=\mathrm{Br}$, In, THF- $\mathrm{H}_{2} \mathrm{O}$,r.t.

$\mathrm{X}=\mathrm{SnBu}_{3}, \mathrm{BF}_{3} \cdot \mathrm{OEt}_{2}, \mathrm{CH}_{2} \mathrm{Cl}_{2}-78{ }^{\circ} \mathrm{C} \quad 65$

$\begin{array}{rrrrr}25 & : & 0 & : & 0(90 \%) \\ & & & & \\ 53 & \vdots & 21 & \vdots & 8(65 \%) \\ 51 & \vdots & 15 & \vdots & 4(80 \%) \\ 35 & : & 0 & : & 0(76 \%)\end{array}$

Figure 31. Allylation of sugar-derived aldehyde.

with cytotoxic activity against tumor cells in vitro. Its stereochemical structure was recently confirmed. ${ }^{59}$ These two macrolactones possesses the macrocyclic cores that may be constructed from a common homoallylic moiety (Figure 30).

Using a sugar-derived aldehyde as a chiral substrate, four isomers are possible from an allylation reaction. It was found, after optimization, that a $\mathrm{Sn} / \mathrm{NaI} / \mathrm{TBAI}$ aqueous system gave the best yield and selectivity for the desired product. ${ }^{60}$ Other systems tested either resulted in cleavage of the acetal group or a lesser selective reaction giving a mixture of isomers. The stereochemical outcome was explained by a non- $\alpha$-chelation control in the reaction pathway.

\subsection{Dysiherbaine}

Dysiherbaine is a neurotoxic amino acid isolated from Dysidea herbacea. ${ }^{61}$ Several groups had approached the total synthesis of this compound. ${ }^{62}$ However, our strategy is to obtain the advanced intermediate of dysiherbaine stereoselectively through an allylation of a keto-ester (Figure 32). This was based on our earlier work on the stereoselective synthesis of chiral amino alcohols via a Mukaiyama aldol reaction ${ }^{63}$. The stereochemical control on such substrates was proposed to occur through $\pi$-stacking interactions between the carbonyl and aromatic ring, hence imparting facial selectivity to the approach of the nucleophile (Figure 33).

Prior to the actual synthesis of our targeted advanced intermediate, the reaction was studied with a series of substrates. ${ }^{64}$ Results show that the THF/ $\mathrm{H}_{2} \mathrm{O}$ and methanol reaction media are superior, in terms of yield and diastereoselectivities, to that of DMF (Figure 34). In applying this methodology to the synthesis of the advanced intermediate of dysiherbaine, only a single desired isomer was obtained. ${ }^{65}$

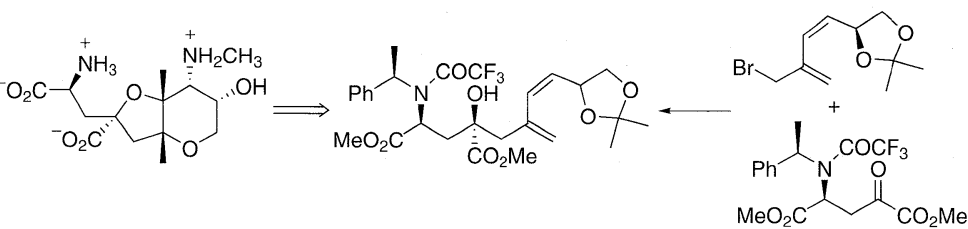

Figure 32. Retrosynthetic analysis of Dysiherbaine.

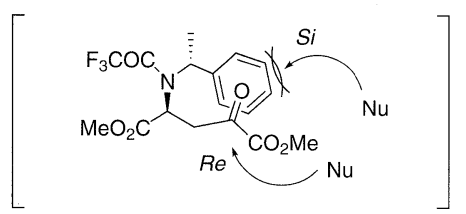

Figure 33. Facial selectivity of proposed substrate for allylation. 


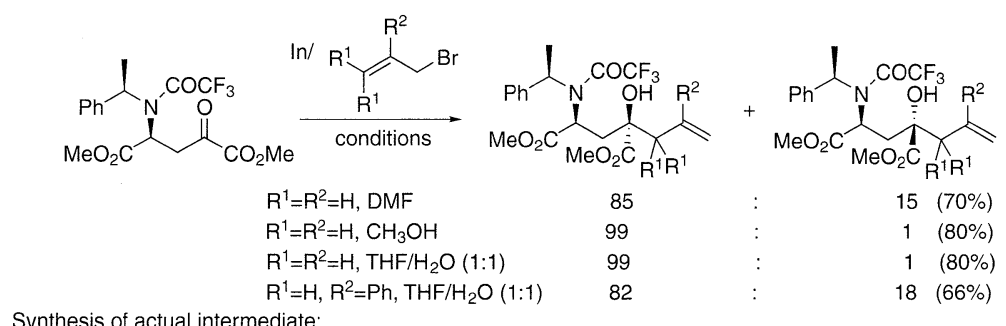

Synthesis of actual intermediate:

$\mathrm{R}^{1}=\mathrm{H} \quad \mathrm{R}^{2}=\mathrm{THF}_{\mathrm{H} / \mathrm{H}} \mathrm{O}(1: 1) \quad 72 \%$ yield

not detected

Figure 34. Results of allylation of $\beta$-amino keto-ester.

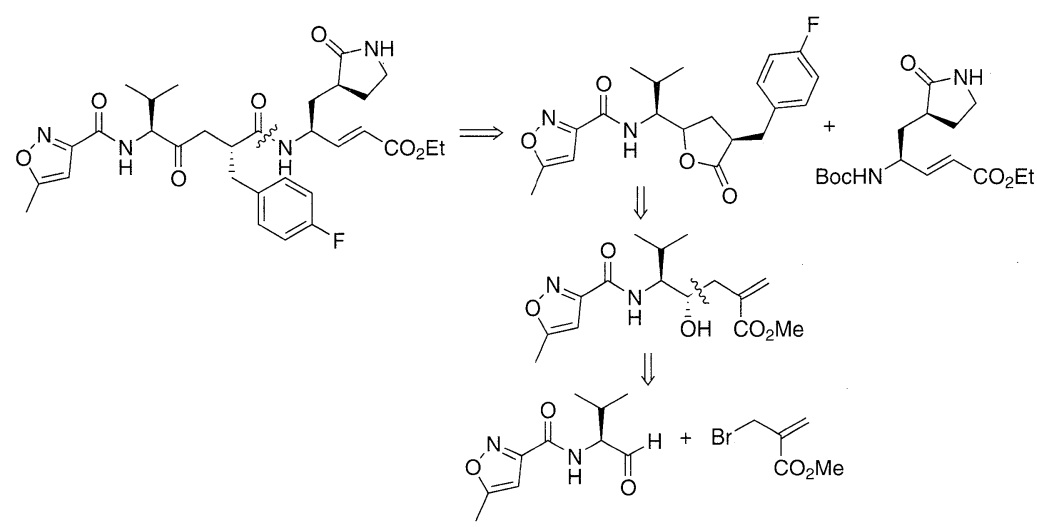

Figure 35. Retrosynthetic analysis of AG7088.

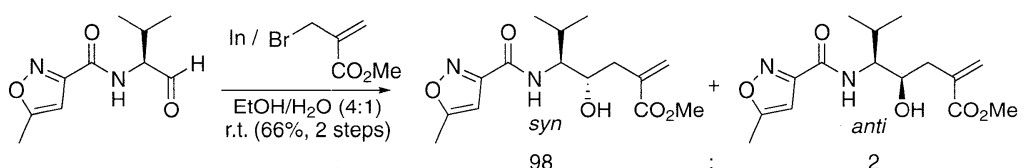

Figure 36. Allylation of $\beta$-amino aldehyde.

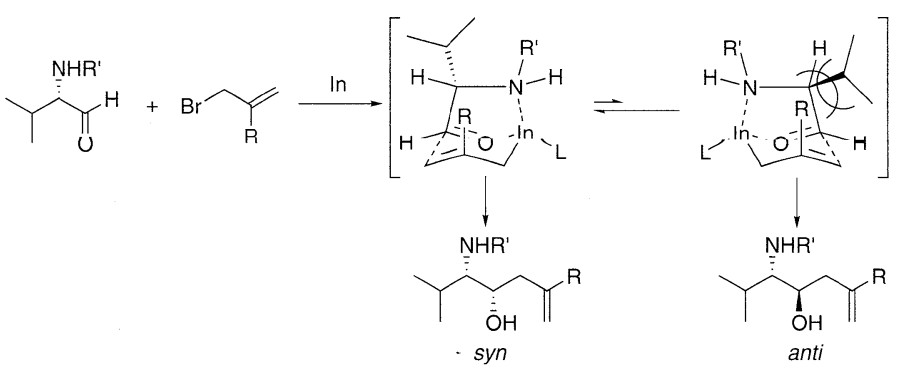

Figure 37. Proposed mechanism for allylation.

\subsection{AG7088}

AG7088 is a HRV $3 C^{\text {pro }}$ inhibitor that inhibits the proteinases of coronaviruses. This compound is thus a potential cure for the "common cold" and modifications of it may be a remedy for Severe Acute Respiratory Syndrome. This compound may be derived from two fragments, with one of the fragments obtained from a stereospecific allylation (Figure $35)$.

Using an indium-mediated allylation reaction in a medium of EtOH/ $\mathrm{H}_{2} \mathrm{O}$, the desired syn product was obtained in good yield and unusually high selectivity (Figure 36). ${ }^{66}$ This diastereoselectivity may be explained through a Felkin-Anh chelation model in which steric repulsion between the isopropyl group and the $\mathrm{CO}_{2} \mathrm{Me}$ group may account for the disfavour of one of the transition states (Figure 37).
However, from the report by Steurer and Podlech ${ }^{67}$ and our experience, there may be an additional factor contributing to such high selectivity besides the proposed steric repulsion. By looking at the substrate structure, the isoxazole group on the $\alpha$-amino group may most likely be participating in the transition state. A study with other amino protecting groups had borne out this fact (Figure 38).

The contribution to the increased diastereoselectivity by the isoxazole moiety may be the greater rigidity of the transition state imparted through its additional coordination with the indium centre by the isoxazole nitrogen (Figure 39). This would reduce the stability of the sterically disfavoured transition state even further by preventing the interacting groups from moving away from one another. An unusually high syn selectivity is therefore observed. 


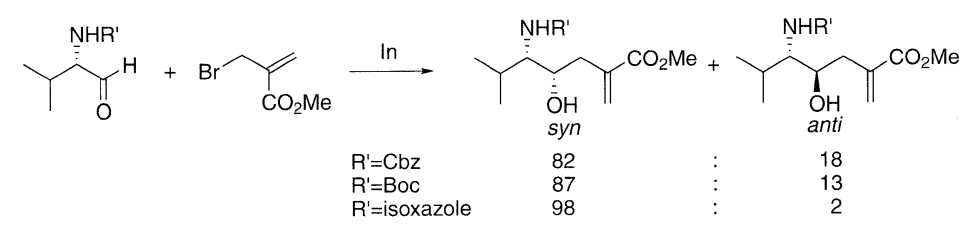

Figure 38. Substituent on $\alpha$-amino group influencing stereoselectivity.

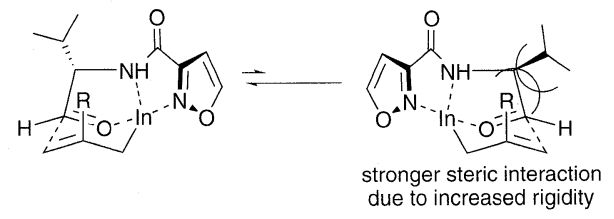

Figure 39. Mechanism to account for the participation of isoxazole group.

\section{Conclusion}

Adaptations of carbon-carbon bond forming reactions from strictly anhydrous to aqueous media have been intensely studied in recent years, in part driven by the "green chemistry" movement. Our group's work on allylation in such reactions have demonstrated the feasibility of such systems to closely mimic or even surpass that of traditional Grignard and similar reactions. The challenge and general direction is to develop enantioselective systems that are effective in aqueous media. Routing such chemistries to the synthesis of natural products and other biologically active compounds would bring us to the ultimate "enzyme mimic", and efforts are still being made to this end in our laboratory.

\section{References}

1) Recent review on indium mediated reactions: Ranu, B. C. Eur. J. Org. Chem. 2000, 2347.

2) "Main Group Metals in Organic Synthesis" ed by Yamamoto, H.; Oshima, K.; John Wiley \& Sons (2004).

3) Roush, W. R. "Comprehensive Organic Synthesis" ed by Trost, B. M.; Fleming, I.; Heathcock, C. H. Pergamon Press, Oxford (1991), Vol. 2.

4) Yamamoto, Y.; Asao, N. Chem. Rev. 1993, 93, 2207.

5) For example, see Arefolov, A.; Panek, J. S. J. Am. Chem. Soc. $\mathbf{2 0 0 5}, 127,5596$

6) For example, see Julian, L. D.; Newcom, J. S.; Roush, W. R. J. Am. Chem. Soc. 2005, 127, 6186.

7) For example, see Felpin, F.-X.; Boubekeur, K.; Lebreton, J. J. Org. Chem. 2004, 69, 1497.

8) For example, see Crimmins, M. T.; Powell, M. T. J. Am. Chem. Soc. 2003, 125, 7592.

9) Wang, R.; Lim, C.-M.; Tan, C.-H.; Lim, B.-K.; Sim, K.-Y.; Loh, T.-P. Tetrahedron: Asymmetry 1995, 6, 1825.

10) Recent review: Kobayashi, S.; Sugiura, M.; Kitagawa, H.; Lam, W. W.-L.; Chem. Rev. 2002, 102, 2227.

11) (a) Chérest, M.; Felkin, H.; Prudent, N. Tetrahedron Lett. 1968 , 2199. (b) M. Cherest; H. Felkin Tetrahedron Lett. 1968, 9, 2205. (c) Anh, N. T.; Eisenstein, O. Nouv. J. Chim. 1976, 1, 61. (d) Anh, N. T. Top. Curr. Chem. 1980, 88, 145.

12) Cram, D. J.; Abd Elhafez, F. A. J. Am. Chem. Soc. 1952, 74, 5828.

13) (a) Cram, D. J.; Kopecky, K. R. J. Am. Chem. Soc. 1959, 81, 2748. (b) Cram, D. J.; Wilson, D. R. J. Am. Chem. Soc. 1963, $85,1249$.

14) Loh, T.-P.; Wang, R.-B.; Tan, K.-L.; Sim, K.-Y. Main Group Metal Chem. 1997, 20, 237.

15) Loh, T.-P.; Ho, D. S.-C.; Chua, G.-L.; Sim, K.-Y. Synlett 1997, 563.

16) Li, X.-R.; Loh, T.-P. Tetrahedron: Asymmetry 1996, 7, 1535.

17) Recent review on indium salts in organic synthesis: (a) Frost, C. G.; Hartley, J. P.; Mini-Reviews in Organic Chemistry 2004, 1, 1. (b) see ref. 1 .
18) "Organofluorine Chemistry" ed by Banks, R. E.; Smart, B. E. Tatlow, J. C., Plenum Press, New York and London (1993).

19) Loh, T.-P.; Li, X.-R. Angew. Chem. Int. Ed. Engl. 1997, 36, 980.

20) Loh, T.-P.; Li, X.-R. Eur. J. Org. Chem. 1999, 1893.

21) Loh, T.-P.; Li, X.-R. Tetrahedron 1999, 55, 5611.

22) Loh, T.-P.; Xu, J. Tetrahedron Lett. 1999, 40, 2431.

23) Loh, T.-P.; Xu, J.; Hu, Q.-Y.; Vittal, J. J. Tetrahedron: Asymmetry 2000, $11,1565$.

24) Loh, T.vP.; Tan, K.-T.; Yang, J.-Y.; Xiang, C.-L. Tetrahedron Lett. 2001, 42, 8701.

25) Isaac, M. B.; Chan, T.-H. Tetrahedron Lett. 1995, 36, 8957.

26) Hirashita, T.; Yamamura, H.; Kawai, M.; Araki, S. Chem. Commun. 2001, 387.

27) Araki, S.; Katsumura, N.; Butsugan, Y. J. Organomet. Chem. 1991, $415,7$.

28) Loh, T.-P.; Tan, K.-T.; Hu, Q.-Y. Tetrahedron Lett. 2001, 42, 8705 .

29) (a) Yamamoto, Y.; Maruyama, K. J. Org. Chem. 1983, 48, 1565. (b) Keck, G. E.; Abbott, D. E.; Boden, E. P.; Enholm, E. J. Tetrahedron Lett. 1984, 25, 3927. (c) Yamamoto, Y.; Maeda, N.; Maruyama, K. Chem. Commun. 1983, 9, 742. (d) Gambaro, A.; Ganis, P.; Marton, D.; Peruzzo, V.; Tagliavini, G. J. Organomet. Chem. 1982, 231, 307.

30) (a) see ref 25. (b) Benkeser, R. A.; Siklosi, M. P.; Mozdzen, E. C. J. Am. Chem. Soc. 1978, 100, 2134.

31) Review: Ripoll, J. L.; Vallée, Y. Synthesis, 1993, 659.

32) (a) Nokami, J.; Yoshizane, K.; Matsuura, H.; Sumida, S.-I. J. Am. Chem. Soc. 1998, 120, 6609. (b) Sumida, S.-I.; Ohga, M.; Mitani, J.; Nokami, J. J. Am. Chem. Soc. 2000, 122, 1310.

33) Tan, K.-T.; Chng, S.-S.; Cheng, H.-S.; Loh, T.-P. J. Am. Chem. Soc. 2003, 125, 2958

34) Loh, T.-P.; Hu, Q.-Y.; Ma, L.-T. J. Am. Chem. Soc. 2001, 123, 2450.

35) Loh, T.-P.; Tan, K.-T.; Hu, Q.-Y. Angew. Chem. Int. Ed. 2001, 40, 2921

36) (a) Cheng, H.-S.; Loh, T.-P. J. Am. Chem. Soc. 2003, 125, 4990. (b) Loh, T.-P.; Lee, C.-L. K.; Tan, K.-T. Org. Lett. 2002, 4, 2985. (c) Loh, T.-P.; Hu, Q.-Y.; Chok, Y.-K.; Tan, K.-T. Tetrahedron Lett. 2001, 42, 9277.

37) (a) Loh, T.-P.; Hu, Q.-Y.; Ma, L.-T. Org. Lett. 2002, 4, 2389. (b) Lee, C.-L. K.; Lee, C.-H. A.; Tan, K.-T.; Loh, T.-P. Org. Lett. 2004, 6, 1281. (c) Lee, C.-H. A.; Loh, T.-P. Tetrahedron Lett. 2004, 45, 5819.

38) (a) Loh, T.--P.; Zhou, J.-R.; Yin, Z. Org. Lett. 1999, 1, 1855. (b) Loh, T.-P.; Zhou, J.-R.; Li, X.-R. Tetrahedron Lett. 1999, 40, 9333.

39) (a) Nishiyama, H.; Kondo, M.; Nakamura, T.; Itoh, K. Organometallics 1991, 10, 500. (b) Nishiyama, H.; Yamaguchi, S.; Kondo, M.; Itoh, K. J. Org. Chem. 1992, 57, 4306.

40) Review: Ghosh, A. K.; Manhivanan, P.; Cappiello, J. Tetrahedron: Asymmetry 1998, 9, 1.

41) Loh, T.-P.; Zhou, J.-R. Tetrahedron Lett. 1999, 40, 9115.

42) (a) Yanagisawa, A.; Nakashima, H.; Ishiba, A.; Yamamoto, H. J. Am. Chem. Soc. 1996, 118, 4723. (b) Yanagisawa, A.; H. Kageyama; Nakatsuka, Y.; Asakawa, K.; Matsumoto, Y.; Yamamoto, H. Angew. Chem. Int. Ed. Engl. 1999, 38, 3701.

43) Teo, Y.-C.; Tan, K.--T.; Loh, T.-P. Chem. Commun. 2005, 1318. 
44) Lu, J.; Ji, S.-J;; Teo, Y.-C.; Loh, T.-P. Org. Lett. 2005, 7, 159

45) Orjala, J.; Nagle, D. G.; Hsu, V. L.; Gerwick, W. H. J. Am Chem. Soc. 1995, 117, 8281 .

46) (a) Yokokawa, F.; Shioiri, T. J. Org. Chem. 1998, 63, 8638. (b) Yokokawa, F.; Fujiwara, H.; Shioiri, T. Tetrahedron Lett. 1999 40, 1915. (c) Yokokawa, F.; Fujiwara, H.; Shioiri, T. Tetrahe dron 2000, 56, 1759. (d) White, J. D.; Hanselmann, R.; Wardrop, D. J. Am. Chem. Soc. 1999, 121, 1106.

47) Loh, T.-P.; Cao, G.-Q.; Pei, J. Tetrahedron Lett. 1998, 39, 1453.

48) Loh, T.-P.; Cao, G.-Q.; Pei, J. Tetrahedron Lett. 1998, 39, 1457.

49) (a) Zimmerman, H. E.; Traxler, M. D. J. Am. Chem. Soc. 1957 79, 1920. (b) Heathcock, C. H. "Asymmetric Synthesis", ed by J. D. Morrison, Academic, New York, Vol.3 (1983).

50) Loh, T.-P.; Yin, Z.; Song, H.-Y.; Tan, K.-L. Tetrahedron Lett. 2003, 44, 911 .

51) Loh, T.-P.; Song, H.-Y. Synlett 2002, 2119.

52) Park, B. K.; Nakagawa, M.; Hirota, A.; Nakayama, M. J. Antibiot. 1988, 6, 751.

53) (a) Simon, J. A. "The Total Synthesis of Natural Products", ed Heathcock, C. H.; Graham, S. L.; Pirrung, M. C.; Plavac, F.; White, C. T.; Wiley: New York, Vol. 5, "The Synthesis of Sesquiterpenes", 1970 (1983). (b) Grieco, P. A.; Ohfune, Y.; Majetich, G. F. J. Org. Chem. 1983, 48, 360. (c) Tanaka, A.; Yamashita, K. Agric. Biol. Chem. 1980, 44, 199. (d) Saicic, R. N.; Zard, S. Z. Chem. Commun. 1996, 1631. (e) Takahata, H.; Uchida, Y.; Momose, T. J. Org. Chem. 1995, 60, 5628. (f) Vaupel, A.; Knochel, P. Tetrahedron Lett. 1995, 36, 231. (g) Honda, T.; Kimura, N. J. Chem. Soc. Chem. Commun. 1994, 77. (h) de Azevedo, M. B.; Murta, M. M.; Greene, A. E. J. Org. Chem. 1992, 57, 4567.

54) Mahato, S. B.; Siddiqui, K. I. A.; Bhattacharya, G.; Ghosai, T.; Miyahara, K.; Sholichin, M.; Kawasaki, T. J. Nat. Prod. 1987, $50,245$.

55) Zhang, Z.; Lu, X. Tetrahedron: Asymmetry 1996, 7, 1923.

56) (a) Kim, J. W.; Adachi, H.; Shin-Ya, K.; Hayakawa, Y.; Seto, H. J. Antibiot. 1997, 50, 628. (b) Hayakawa, Y.; Kim, J. W.; Adachi, H.; Shin-ya, K.; Fujita, K.-i.; Seto, H. J. Am. Chem. Soc. 1998, 120, 3524

57) (a) Nicolaou, K. C.; Li, Y.; Fylaktakidou, K. C.; Mitchell, H. J.; Weyershausen, B.; Wei, H. X. Angew. Chem. Int. Ed. 2001, 40 3849. (b) Nicolaou, K. C.; Li, Y.; Fylaktakidou, K. C.; Mitchell, H. J.; Sugita, K. Angew. Chem. Int. Ed. Engl. 2001, 40, 3854 .

58) (a) Seki-Asano, M.; Okazaki, T.; Yamagishi, M.; Sakai, N.; Hanada, K.; Mizoue, K. J. Antibiot. 1994, 47, 1226. (b) SekiAsano, M.; Tsuchida, Y.; Hanada, K.; Mizoue, K. J. Antibiot. 1994, 47, 1234

59) Eguchi, T.; Kobayashi, K.; Uekusa, H.; Ohashi, Y.; Mizoue, K.; Matsushima, Y; Kakinuma, K. Org. Lett. 2002, 4, 3383.

60) Chng, S.-S.; Xu, J.; Loh, T.-P. Tetrahedron Lett. 2003, 44, 4997.

61) Sakai, R.; Kamiya, H.; Murata, M.; Shimamoto, K. J. Am. Chem. Soc. 1997, 119, 4112

62) (a) Snider, B. B.; Hawryluk, N. A. Org. Lett. 2000, 2, 635. (b) Masaki, H.; Maeyame, J.; Kamada, K.; Esumi, T.; Iwabuchi, Y.; Hatakeyama, S. J. Am. Chem. Soc. 2000, 122, 5216. (c) Sasa- ki, M.; Koike, T.; Sakai, R.; Tachibana, K. Tetrahedron Lett. 2000, 41, 3923

63) Loh, T.-P.; Huang, J.-M.; Goh, S.-H.; Vittal, J.-J. Org. Lett. 2000, 2, 1291.

64) Loh, T.-P.; Huang, J.-M.; Xu, K.-C.; Goh, S.-H.; Vittal, J.-J Tetrahedron Lett. 2000, 41, 6511.

65) Huang, J.-M.; Xu, K.-C.; Loh, T.-P. Synthesis 2003, 755.

66) Chng, S.-S.; Hoang, T.-G.; Lee, W.-W. W.; Tham, M.-P.; Ling, H. Y.; Loh, T.-P. Tetrahedron Lett. 2004, 45, 9501.

67) Steurer, S.; Podlech, Eur. J. Org. Chem. 1999, 1551.

\section{PROFILE}

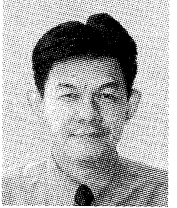

Loh Teck-Peng is a Professor of chemistry in Nanyang Technological University, School of Physical and Mathematical Sciences. He was born in Malaysia in 1962. He received his B. Sc. (1987) and M. Sc. (1989) from the Tokyo Institute of Technology. He had worked with Professor Takeshi Nakai and Professor Koichi Mikami for his research work there. Under the tutelage of Professor E. J. Corey, Professor Loh obtained his $\mathrm{Ph}$. D (1994) from Harvard University. In 1994, he joined the National University of Singapore as a Lecturer, in 1999 as an Associate Professor and in 2004 as a full Professor. Professor Loh then moved to Nanyang Technological University in 2005 and is currently a Professor and the Head of Division (Chemistry and Biological Chemistry, School of Physical and Mathematical Sciences). His research interests are in the area of enantioselective reactions, development of new synthetic methodologies especially in the area of Green chemistry, and the total synthesis of natural products.

Chua Guan-Leong is born in Singapore in 1971. He obtained his B. Sc. (1992) and Ph. D (2001) from the National University of Singapore, working under the guidance of Professor Loh TeckPeng. He had worked in the industry for 5 years before joining Nanyang Technological University in 2005 as a Lecturer. $\mathrm{His}$ research interest is in synthesis methodologies. 